\title{
Impact of social standing on traffic injury prevention in a WHO safe community
}

\author{
Kent Lindqvist ${ }^{1^{*}}$, Koustuv Dalal $^{2}$ \\ ${ }^{1}$ Department of Medical and Health Sciences, Division of Social Medicine and Public Health Science, Linkoping University, Lin- \\ koping, Sweden; ${ }^{*}$ Corresponding Author: kent.lindqvist@liu.se \\ ${ }^{2}$ School of Health \& Medical Sciences, Department of Public Health Science, Örebro University, Örebro, Sweden
}

Received 5 November 2011; revised 7 December 2011; accepted 23 December 2011

\begin{abstract}
The objective of the current study was to evaluate outcomes of a program to prevent traffic injuries among the different social strata under WHO Safe Community Program. A quasi-experimental design was used, with pre- and postimplementation registrations in the program implementation area (population 41,000) and in a neighbouring control municipality (population 26,000) in Östergötland County, Sweden. The traffic injury rate in the not vocationally active households was twice than employed or selfemployed households in the intervention area. In the employed and not vocationally active households, males showed higher injury rates than females in both areas. In the self-employed households females exhibited higher injury rates than males in the intervention area. Males from not vocationally active households displayed the highest post-intervention injury rate in both the intervention and control areas. After 6 years of Safe Community program activity, the injury rates for males in employed category, injury rates for females in self-employed category, and males/females in non-vocationally active category displayed a decreasing trend in the intervention area. However, in the control area injury rate decreased only for males of employed households. The study indicated that there was almost no change in injury rates in the control area. Reduction of traffic injuries in the intervention area between 1983 and 1989 was likely to be attributable to the success of safety promotion program. Therefore, the current study concludes that Safe Community program seems to be successful for reducing traffic injuries in different social strata.
\end{abstract}

This study was supported by grants from the Swedish Civil Contingencies Agency (MSB).
Keywords: Traffic Injury; Socioeconomic Index; Evaluation; Safe Community; Sweden

\section{INTRODUCTION}

Traffic injuries is one of the most common preventable causes of death and disability worldwide with great burden on communities and health care systems worldwide $[1,2]$. Traffic injuries present a higher than average rate of serious injury than any other type [3]. Studies of traffic injuries by severity suggest that the socioeconomic determinants of more severe injuries differ from those of less severe injuries [1]. However, less we know about the traffic injury prevention programs especially in relation to socioeconomic status of the victims' families.

Community based programs to prevent common nonfatal injuries have been effectively implemented as complements to various national safety programs $[2,4]$. Because official statistics give only a general idea of the traffic injury situation in Sweden, more detailed registration is required. Data from a limited geographical area can provide important information for comparison and, not least, for planning injury prevention work [5]. The current study was developed following the World Health Organization (WHO) Safe Community program (more details at http://www.phs.ki.se/csp/). Using a quasi-experimental design to compare intervention and control communities, the study investigated changes in the allcause traffic injury risk after program implementation. In addition, changes in the distribution of injury severity and injury event contexts in the intervention community were examined [2]. An assessment of the general structure and process of the program has previously been reported [6]. In Sweden, the positioning of the local government in the program structure appears to be the most important factor determining program effectiveness.

WHO (2004) has published the world report on traffic injuries and provided a call for drastic actions for traffic injury prevention [1]. WHO Safe Communities program has been operating for the last two decades to prevent injuries and promote safety. Earlier study indicated that, 
the relative risk for moderate traffic injuries have decreased by almost half in a WHO Safe Community in Sweden without focusing socioeconomic determinants [2]. Injuries especially have been reported to be more common in households with poorer social strata $[7,8]$. Vulnerable populations living in poor social strata are disproportionately at a risk of injury [9-12]. However, to the best of authors' knowledge, few studies to date have investigated the impact of traffic injury prevention programs on males and females from different social strata.

The objective of the current study was to investigate differences in the distribution of the traffic injury rate reduction among the different social strata in the catchment area. Specifically, the aim was to study, using a quasi-experimental design [13], rates of victims of traffic injury treated by healthcare organizations among members of households at different levels of labour market integration before and after program implementation.

\section{METHODS}

The Motala community is one of the original reference sites for the World Health Organization (WHO) Safe Community accreditation criteria. The Safe Community concept was developed in Sweden in conjunction with the WHO, based on findings from local Swedish injury prevention programs in the 1970s and 1980s. Scandinavian countries were among the first to implement the Safe Community model in the late 1980s and early 1990s [14]. The model emphasizes community participation and multidisciplinary collaboration, recognizing that those most able to solve local injury problems are those people who live in that particular community [4].

\subsection{Study Design}

A quasi-experimental design was used, with pre- and post-implementation registrations in the program implementation area (Motala) and in a neighbouring control municipality (Mjölby) in Östergötland County. The preimplementation study period covered 52 weeks from 1 October 1983 to 30 September 1984. The post-implementation period covered 52 weeks from 1 January 1989 to 31 December 1989. Changes in the morbidity rates following the intervention were studied using prospective registration of all acute care episodes during the study period. The intervention area had four health care centers and a county annex hospital with a casualty department, while the control area shared the annex hospital and had two health care centers, one with an emergency unit.

\subsection{Implementation of the Motala Program}

The theoretical framework for the program is based on a participative strategy for community involvement.
Using national injury prevention programs as a background, the preventive actions rely on local community aims and resources. The program goals include: organization of a local cross-sectoral action group; reliance on existing local community networks; and continuous tracking of high-risk environments and groups.

Regarding traffic injuries, the aim of the community analysis stage of the program [15], performed in 19831984 , was to study the local epidemiology of traffic injuries, to follow the economic consequences of the injuries, and to analyze the local social structure and values [5,6]. Stage two, the program design and initiation (1985-1987) included organizing the management of the intervention and setting local planning goals. The district Health Services Board, the Municipal Board, and political committees and management groups were approached to accept responsibility for program actions. The goal set for the program was to reduce the total injury incidence in the municipality by $25 \%$ by the year 2000 . The design evolved into a program of action during the implementation stage (1987-1988). The planning and content of prevention work was guided by a Traffic Safety Council made up of 20 delegates representing the municipality departments with responsibility for road maintenance, urban planning, schools, child care and care of the elderly, the National Road Safety Office, the National Road Administration, the Swedish Road and Traffic Research Institute, and the local police department. This group had regular meetings twice a year. From the Traffic Safety Council, a task force meeting each month was held, consisting of representatives from the police, schools, parents' organizations, the municipality road maintenance office, and local motor organizations. For structural changes, the task force used two main sources of reference; the Swedish guidelines for urban planning and traffic safety (SCAFT) and an updated geographical inventory of local trouble spots. With these as a background, changes in the physical environment were suggested and implemented. The focus was on free foot spaces and traffic calming spaces in residential areas. For example, a "Safe way to school" program to identify and adjust trouble spots was performed with the cooperation of the primary schools and the municipality’s planning department, and a "Cut your garden hedge” initiative was promoted to increase driveway visibility in residential areas. However, measures were also directed towards motor transport spaces, e.g. by improvements in the winter road maintenance. Concerning education, the focus was on teaching traffic rules and safety norms to children and teenagers. Voluntary organizations and the police arranged traffic education programs aimed at primary and lower-secondary school levels. A 1-hour traffic lesson was scheduled every week for all fourth-graders. In addition, a bicycling safety pro- 
gram was initiated in which parents of 5-years-old were able to buy a helmet at a subsidized price, and where bike helmet use was promoted among primary school children. Furthermore, courses were offered for school children to "shape up your bike". Combined actions were focused on specific areas. A child safety seat loan program was developed as a demonstrator project and a falling prevention program was composed for the elderly.

\subsection{Classification of Data}

The Swedish Socio-economic Index (SEI) was used to classify the individuals in the study areas. The SEI was used since the early 1980s to represent social status in most national databases and statistics [16]. The SEI defines social status primarily as being based on occupation. Children and young people are categorized to the SEI group to which their parents' household belongs.

SEI data for all individuals in the intervention and control areas were collected from Statistics Sweden (http://www.scb.se). Due to the changes in socio-economic household circumstances concerning retirement from work, individuals older than 65 years of age were excluded from the current study [17]. For the pre-implementation measurement, SEI data originated in the Census survey conducted in 1985. Corresponding data for the post-implementation measurement originated in the 1990 Census survey.

Considering that the WHO Safe Community model relies strongly on the existing civic social network, and that occupation is an important determinant for these networks, the detailed SEI categories were used for coding individuals into three secondary categories based on the relation that the household had to the labour market: 1) households in which the vocationally significant member was employed, i.e. the person in the household with the highest wage earnings; 2) households in which the vocationally significant member was an entrepreneur or self-employed; and 3) households in which the adults were not vocationally active.

\subsection{Community Characteristics}

Motala is situated in the western part of the county of Östergötland. The population was approximately 41,000 during the study period (82\% living in the central and residential areas and the $18 \%$ living in surrounding rural areas). Seventy seven percent were gainfully employed in the field of manufacturing, trade and public administration. Mjölby, control municipality area, (population 26,000 ), was selected on the basis of socio-economic and demographic similarities to Motala and obviously due to availability of injury data. The city of Mjölby is situated $30 \mathrm{~km}$ south of Motala in the same county in the southeastern part of Sweden.

\subsection{Data Collection}

All traffic injured persons arriving at any health care unit located in the intervention and control areas during the study periods were included in to the current study. The nature and event context of injuries was classified using the International Classification of Diseases, eighth revision [18], and the abbreviated injury scale (AIS) was used to measure injury severity [19]. Based on information from medical records two specially trained nurses classified injuries after the care episode. The attending physician was asked to verify, whenever necessary the accuracy of the classification. However, due to a lack of resources data on injury severity and event context were not collected from the control area [20].

Traffic injuries were defined in the present study as, first, injuries sustained in accidents involving at least one vehicle of any kind and, second, pedestrians injured in an accident not involving another person or vehicle, e.g. an injury caused by slipping or stumbling [2]

To estimate the quality of the specific injury registration procedure, secondary sampling of all acute health care attendances in the intervention area was undertaken during the third week of the pre-implementation registration period and in both the intervention and control areas during the third week of the post-implementation registration period. University hospital emergency department records from September 1984 were also additionally analyzed for any systematic differences between persons from the intervention and control areas receiving care outside the care units providing data for this evaluation.

\subsection{Statistical Methods}

Injury rates, expressed as per 100 person-years, were calculated by community (intervention and control municipality) for each study period (1983/1984 and 1989), by socio-economic group according to labour market: employed, self-employed and not vocationally active; and by gender [21]. Ninety-five percent confidence intervals (CI) were employed for injury rates. To avoid double registration of the same injury, only the first episode of injury during each registration period was included in the calculations. However, if the victim had any new other injury during the registration period, that was registered in the current study. The differences in injury rates between 1989 and 1983/1984 were computed for both areas with $95 \%$ CI. Similarly, differences in changes of injury rate between the intervention and control areas were computed using the following expression.

Difference in changes of injury rate $=[$ Post-intervention injury rate in intervention area - Pre-intervention injury rate in intervention area] - [Post intervention injury rate in control area - Pre-intervention injury rate in 
control area]

The differences in injury rates (within each area over time, and between areas in 1983/1984) were compared using the two-sided z-test for difference between two proportions [22]. A P-value $<0.05$ was employed to test the level of statistical significance.

All computations were performed using SPSS statistical software (PASW Statistics, Version 18).

\subsection{Ethical Permission}

The study was approved by the Regional Committee for Research Ethics at Linkoping University, Sweden.

\section{RESULTS}

\subsection{Environmental Indicators}

The total number of hospital-treated traffic accident victims in Sweden increased by $15 \%$ from 10650 to 12250 between 1984 and 1989, while the number of traffic-related deaths remained constant. The age and sex mix in both the intervention and control area was stable between the registration periods and was close to the national average. Residential and income characteristics also remained stable. The educational level in both areas was slightly below the national average but showed a tendency to increase. The number of motor vehicles owned by residents increased by $12 \%$ in the intervention area and by $13 \%$ in the control area. No extraordinary weather conditions were observed during any of the study periods.

\subsection{Quality of Registrations}

During the pre-implementation registration period, which also includes non-traffic injuries, identity data were missing for 18 of the 4926 injured patients $(0.4 \%)$ in the intervention area and $23(0.9 \%)$ of the 2694 injured patients in the control area. During the post-implementation period, which also includes non-traffic injuries, ten of the 4287 injured patients $(0.2 \%)$ in the intervention area could not be identified in the medical records. For six of the 2746 injured patients $(0.2 \%)$ in the control area, identity data were missing.

In the registration control during the pre-implementation period, five (5\%) of the 102 injuries observed secondarily were found not to have been registered in the intervention area, three had, mistakenly, not been registered as injuries and two others were found not to have been recorded. During the post-implementation period in the intervention area, four (5\%) of 84 injuries observed secondarily had not been registered, these had not been recorded. In the control area, seven (14\%) of 51 secondarily observed injuries had not been registered, three had, mistakenly, not been registered as injuries and four others had not been recorded.

A lower share of all injured residents from the intervention area $(11 / 422,3 \%)$, than from the control area (28/253, 12\%), was found to have been directly provided with acute care at the university hospital during the month of the control study.

During 1983-1984, traffic injury rates were 1.5 per 100 population years in the intervention area, and 0.9 per 100 population years in the control area. This difference is due, in part, to the lower proportion of injured residents from the intervention area than in the control area seeking emergency care at the university hospital.

\subsection{Pre-Intervention Injury Rates}

The traffic injury rate in the not vocationally active households were twice than employed or self-employed households in the intervention area (Table 1). No such differences could be find in the control area. In the employed and not vocationally active households, males showed higher injury rates than females in both areas. In the self-employed households females exhibited higher injury rates than males in the intervention area. The preintervention injury rates were noticeably higher in the intervention area than in the control area for all three socio-economic groups with the exception for males in self-employed households.

\subsection{Post-Intervention Injury Rates}

Males from not vocationally active households displayed the highest post-intervention injury rate in both the intervention and control area (Table 2). Also in selfemployed households, males showed higher injury rates than females in the intervention area. However, in those households traffic injury rates of females were increased in the control area compared to intervention area. After 6 years of Safe Community program activity, the injury rates for males in employed category, injury rates for females in self-employed category, and males/females in non vocationally active category displayed a decreasing trend in the intervention area. However, in the control area injury rate decreased only for males of employed households.

\section{DISCUSSION}

The current study indicates that Safe Community program seems to be successful for reducing traffic injuries in different social strata. The study analyzed the WHO Safe Community program for traffic injury prevention and safety promotion with regard to associations between pre- and post-intervention injury rates among male and female, and socio-economic status, as defined by the labour market employment category of the household's significant member. 
Table 1. Rate per 100 person-years (95\% confidence interval) of individuals injured in traffic in 1983/1984 in intervention and control areas, displayed by sex and household relation to labor market employment.

\begin{tabular}{ccccccccccc}
\hline & \multicolumn{3}{c}{ Employed } & \multicolumn{3}{c}{ Self-employed } & \multicolumn{3}{c}{ Not vocationally active } \\
\cline { 2 - 11 } & Male & Female & Total & Male & Female & Total & Male & Female & Total \\
\hline \multirow{2}{*}{ Intervention area } & 1.7 & 1.2 & 1.4 & 1.2 & 1.5 & 1.3 & 3.0 & 2.5 & 2.7 \\
& $(1.4,1.9)$ & $(1.0,1.3)$ & $(1.3,1.5)$ & $(0.7,1.8)$ & $(0.7,2.3)$ & $(0.9,1.8)$ & $(2.2,3.9)$ & $(1.7,3.2)$ & $(2.2,3.3)$ \\
Control area & 1.1 & 0.8 & 0.9 & 1.3 & 1.0 & 1.2 & 1.3 & 1.1 & 1.1 & $(0.1)$ \\
P value & $(0.8,1.2)$ & $(0.6,0.9)$ & $(0.8,1.0)$ & $(0.7,2.0)$ & $(0.3,1.7)$ & $(0.7,1.7)$ & $(1.6,2.0)$ & $(0.5,1.7)$ & $(0.7,1.6)$ \\
& 0.000 & 0.004 & 0.000 & 0.828 & 0.350 & 0.680 & 0.005 & 0.007 & 0.000 \\
\hline
\end{tabular}

Table 2. Rate per 100 person-years (95\% confidence interval) of individuals injured in traffic in 1989 and change in rates between 1989 and 1983/1984 (95\% confidence interval) in intervention and control areas, displayed by sex and household relation to labor market employment.

\begin{tabular}{|c|c|c|c|c|c|c|c|c|c|}
\hline & \multicolumn{3}{|c|}{ Employed } & \multicolumn{3}{|c|}{ Self-employed } & \multicolumn{3}{|c|}{ Not vocationally active } \\
\hline & Male & Female & Total & Male & Female & Total & Male & Female & Total \\
\hline Intervention area & $\begin{array}{c}1.4 \\
(1.2,1.6)\end{array}$ & $\begin{array}{c}1.1 \\
(1.0,1.3)\end{array}$ & $\begin{array}{c}1.3 \\
(1.1,1.4)\end{array}$ & $\begin{array}{c}1.9 \\
(1.2,2.6)\end{array}$ & $\begin{array}{c}0.9 \\
(0.2,1.6)\end{array}$ & $\begin{array}{c}1.5 \\
(1.0,2.1)\end{array}$ & $\begin{array}{c}2.7 \\
(2.0,3.5)\end{array}$ & $\begin{array}{c}1.9 \\
(1.3,2.5)\end{array}$ & $\begin{array}{c}2.3 \\
(1.8,2.8)\end{array}$ \\
\hline Control area & $\begin{array}{c}-0.3 \\
(-0.6,0.0)\end{array}$ & $\begin{array}{c}0.0 \\
(-0.3,0.2)\end{array}$ & $\begin{array}{c}-0.1 \\
(-0.3,0.0)\end{array}$ & $\begin{array}{c}0.7 \\
(-0.3,1.6)\end{array}$ & $\begin{array}{c}-0.6 \\
(-1.6,0.4)\end{array}$ & $\begin{array}{c}0.2 \\
(-0.5,0.9)\end{array}$ & $\begin{array}{c}-0.3 \\
(-1.4,0.8)\end{array}$ & $\begin{array}{c}-0.5 \\
(-1.5,0.4)\end{array}$ & $\begin{array}{c}-0.4 \\
(-1.1,0.3)\end{array}$ \\
\hline$P$ value & 0.065 & 0.850 & 0.130 & 0.152 & 0.265 & 0.568 & 0.611 & 0.276 & 0.286 \\
\hline Control area & $\begin{array}{c}0.9 \\
(0.7,1.0)\end{array}$ & $\begin{array}{c}0.8 \\
(0.6,1.0)\end{array}$ & $\begin{array}{c}0.8 \\
(0.7,0.9)\end{array}$ & $\begin{array}{c}1.3 \\
(0.6,2.0)\end{array}$ & $\begin{array}{c}2.0 \\
(1.0,3.0)\end{array}$ & $\begin{array}{c}1.6 \\
(1.0,2.1)\end{array}$ & $\begin{array}{c}2.3 \\
(1.4,3.2)\end{array}$ & $\begin{array}{c}1.5 \\
(0.8,2.2)\end{array}$ & $\begin{array}{c}1.9 \\
(1.3,2.5)\end{array}$ \\
\hline Change 1989-1983 & $\begin{array}{c}-0.2 \\
(-0.5,0.1)\end{array}$ & $\begin{array}{c}0.0 \\
(-0.2,0.3)\end{array}$ & $\begin{array}{c}-0.1 \\
(-0.3,0.1)\end{array}$ & $\begin{array}{c}0.0 \\
(-1.0,0.9)\end{array}$ & $\begin{array}{c}1.0 \\
(-0.2,2.0)\end{array}$ & $\begin{array}{c}0.4 \\
(-0.4,1.1)\end{array}$ & $\begin{array}{c}1.0 \\
(-0.1,2.2)\end{array}$ & $\begin{array}{c}0.5 \\
(-0.5,1.4)\end{array}$ & $\begin{array}{c}0.7 \\
(0.0,1.5)\end{array}$ \\
\hline$P$ value & 0.225 & 0.915 & 0.400 & 0.940 & 0.108 & 0.325 & 0.090 & 0.323 & 0.052 \\
\hline
\end{tabular}

The socially disadvantaged people as indicated by the SEI categories were at the highest pre-intervention injury risk, indicating that lower socio-economic status is an important risk factor for traffic injury; this is consistent with previous research $[1,23]$. The current study design did not allow for an investigation into the causes of these differences, although a possible explanation could be more prevalent use of road outside the vehicles (walking, cycling etc.) to earn more for better economic sovereignty. Another finding that requires further study is that females in the self-employed category displayed higher injury rates than males after 6 years of program activity in the control area. Probable reason might be that women of those families were more exposed to road traffic with less affluent economic status and hence lack of access to car.

Traffic safety has been pursued by efforts aimed at reducing traffic volume, decreasing the number of injury events, and reducing the harm resulting from injury [24]. The evaluated Safe Community program did not have a predefined focus in any of the area of traffic safety, but have instead a socio-geographic demarcation [2]. Major roads and highways in Sweden are maintained and regulated by national agencies. The Safe Community program did not concentrate on risks at the community level in traffic spaces designated for high-speed vehicles. The program focused on the local neighborhoods, using stru- ctural and educational resources in the community itself to increase safety when residents get from one place to another.

The current study is from a medium size community in Sweden. As the socio-cultural characters vary over the areas, the current findings might suffer from making a general conclusion for Nordic countries. Therefore further evaluations are warranted in other WHO Safe Communities in other low-, medium- and high-income countries. For individuals injured more than once, only the first episode during each registration period was included in the current study. Repetitive injuries of the same nature of the same victim warrant further studies. In future, similar studies are warranted using severity of the injuries. The study has used data from 1983-1989 to measure the changes of traffic injuries according to social status. Though the data seemed to be old but according to intention of the study it should not create any problem in connection to reality. The current context of the study can demand similar studies using recent data. The study has displayed findings on the rate per 100 person-years (95\% confidence interval) of individuals injured in traffic in 1983/1984 and change in rates between 1989 and 1983/1984 (95\% confidence interval) in intervention and control areas, displayed by sex and household relation to labour market employment. However, most of the findings were not statistically significant. Also the study 
could not estimate the adjusted effects of gender, social strata, intervention-control areas and pre-/post-intervention phases. Therefore further studies are warranted considering to overcome those shortcomings.

In conclusion, the Safe Community program seemed to be effective in that it reduced the traffic injury rates in the intervention area in different social strata. Further research on evaluation of the WHO Safe Community programs in association with social strata and traffic injury intervention is also warranted from different Safe Communities in different countries.

\section{REFERENCES}

[1] WHO (2004) World report on road traffic injury prevention. World Health Organization, Geneva.

[2] Lindqvist, K., Timpka, T. and Schelp, L. (2001) Evaluation of inter-organizational traffic injury prevention in a WHO Safe Community. Accident Analysis and Prevention, 33, 599-607. doi:10.1016/S0001-4575(00)00071-3

[3] Lindqvist, K. (1989) Epidemiology of accidents in a Swedish municipality. Accident Analysis Prevention, 21, 33-43. doi:10.1016/0001-4575(89)90047-X

[4] Bjerre, B. and Schelp, L. (2000) The community safety approach in Falun, Sweden-Is it possible to characterise the most effective prevention endeavours and how longlasting are the results? Accident Analysis and Prevention, 32, 461-470. doi:10.1016/S0001-4575(99)00058-5

[5] Lindqvist, K. (1991) Epidemiology of traffic accidents in a Swedish municipality. Accident Analysis and Prevention, 23, 509-519. doi:10.1016/0001-4575(91)90016-X

[6] Lindqvist, K., Timpka, T. and Schelp, L. (1996) Ten years of experiences from a participatory community-based injury prevention program in Motala, Sweden. Public Health, 110, 339-346. doi:10.1016/S0033-3506(96)80005-9

[7] Stokes, M., Ashby, K. and Clapperton, A. (2002) The effect of socio-economic status on injury among Victorians. Hazard, 49, 1-12.

[8] Svanström, L. (2000) Evidence-based injury prevention and safety promotion: State-of-the-art. In: Mohan, D. and Tiwari, G., Eds., Injury prevention and control, Taylor \& Francis, London, 181-198.

[9] Wilkinson, R. and Marmot, M. (1998) Social determinants of health: The solid facts. WHO Regional Office for Europe, Copenhagen.

[10] Laing, G.J. and Logan, S. (1999) Patterns of unintentional injury in childhood and their relation to socio-economic factors. Public Health, 113, 291-294. doi:10.1016/S0033-3506(99)00182-1
[11] Cubbin, C. LeClerc, F.B. and Smith, G.S. (2000) Socioeconomic status and injury mortality: Individual and neighbourhood determinants. Journal of Epidemiology \& Community Health, 54, 517-524. doi:10.1136/jech.54.7.517

[12] Moodie, R. (2002) Reducing health inequalities: Challenges to promoting health and preventing injury. Hazard, 49, 13-20.

[13] Cook, T.D. and Campell, D.T. (1979) Quasi-experimentation. Houghton-Mifflin Co., Boston.

[14] Zhao, Z. and Svanström, L. (2003) Injury status and perspectives on developing community safety promotion in China. Health Promotion International, 18, 247-253. doi:10.1093/heapro/dag020

[15] Bracht, N. and Kingsbury, L. (1990) Community organization principles in health promotion: A five-stage model. In: Bracht, N., Ed., Health Promotion of the Community Level, Sage, Newbury Park. 66-88.

[16] Timpka, T., Nilsen, P. and Lindqvist, K. (2006) The impact of home safety promotion on different social strata in a WHO safe community. Public Health, 120, 427-433. doi:10.1016/j.puhe.2005.12.002

[17] Silventoinen, K. and Lahelma, E. (2002) Health inequalities by education and age in four Nordic countries, 1986 and 1994. Journal of Epidemiology \& Community Health, 56, 253-258. doi:10.1136/jech.56.4.253

[18] National Board of Health and Welfare. (1982) Classification of diseases 1968: Systematic list. Allmänna Förlaget, Stockholm.

[19] American Association for Automotive Medicine. (1980) Joint committee on injury scaling. The abbreviated injury scale-1980 revision. AAAM, Arlington Heights.

[20] Lindqvist, K., Timpka, T., Schelp, L. and Risto, O. (2002) Evaluation of a child safety program based on the WHO Safe Community model. Injury Prevention, 8, 23-26. doi:10.1136/ip.8.1.23

[21] Lindqvist, K., Timpka, T. and Karlsson, N. (2004) Impact of social standing on injury prevention in a World Health Organization Safe Community-Intervention outcome by household employment contract. International Journal of Epidemiology, 33, 605-611. doi:10.1093/ije/dyh093

[22] Kirkwood, B.R. and Sterne, J.A.C. (2003) Medical Statistics. Blackwell Science Ltd., Massachusetts.

[23] Hasselberg, M. and Laflamme, L. (2003) Socioeconomic background and road traffic injuries: A study of young car drivers in Sweden. Traffic Injury Prevention, 4, 249-254. doi:10.1080/15389580309882

[24] Gunnarsson, S.O. (1996) Traffic accident prevention and reduction: review of strategies. IATSS Research, 20, 6-14. 